\title{
Investment in Information and Communication Technology in Agriculture and Soybean Production Stability: The Case of China ${ }^{\dagger}$
}

\author{
Vesna Jablanovic
}

check for updates

Citation: Jablanovic, V. Investment in Information and Communication Technology in Agriculture and Soybean Production Stability: The Case of China. Eng. Proc. 2021, 9, 34. https://doi.org/10.3390/engproc 2021009034

Academic Editors: Charisios Achillas and Lefteris Benos

Published: 13 December 2021

Publisher's Note: MDPI stays neutral with regard to jurisdictional claims in published maps and institutional affiliations.

Copyright: (C) 2021 by the author. Licensee MDPI, Basel, Switzerland This article is an open access article distributed under the terms and conditions of the Creative Commons Attribution (CC BY) license (https:// creativecommons.org/licenses/by/ $4.0 /)$.
Faculty of Agriculture, University of Belgrade, 11080 Belgrade, Serbia; vesnajab@ptt.rs + Presented at the 13th EFITA International Conference, online, 25-26 May 2021.

\begin{abstract}
The paper creates the chaotic soybeans production growth model. This model includes investment in ICTs in agriculture. Further, the paper discovers a sequence of Elliot waves in soyabeans market in China in the period 1991-2015. Investment in information and communication technologies (ICTs) in agriculture improved both the productivity and soybean production stability. The stable convergent fluctuations of soybeans production existed in China in the observed period.
\end{abstract}

Keywords: information and communication technology; agriculture; chaos; Elliot waves

\section{Introduction}

E-agriculture involves designing, developing, and applying new ways to use information and communication technologies (ICTs) with a primary focus on agriculture. Soybean finds a principal place in the agricultural production systems of many countries, including the United States, Brazil, Argentina, China, and India.

It is important to improve access to valuable information that can help agricultural producers and consumers to make the best possible economic decisions and use the resources available in the most productive manner [1].

ICTs that can be used for e-agriculture may include: telephone (interactive voice response); computers and websites (agriculture information and markets); broadcasting (expertise sharing advisory, community); satellite (weather, universal accessibility, remote sensing); mobile (advisory, sales, banking, networking); internet and broadband (knowledge sharing, social media, e-community, banking, market platform, trading, ... ); sensor networks (real time information, better data quality and quantity, decision making), data storage and analytics (precision agriculture ) [1].

Using e-agriculture can lead to greater efficiencies in agricultural extension, disaster risk management and early warning systems, enhanced market access and financial inclusion, etc. Using e-agriculture can improve market information. Lower transaction costs, improved market coordination and more transparent rural markets are results of this type of agriculture [1].

ICTs, GIS, remote sensing, precision farming and many other technologies or processes hold great promises for improved agricultural productivity. Achieving improved and sustainable agricultural production and productivity growth largely depends on the advancement of agricultural research and its effective applications at farmer's fields through the transfer of technology and innovation. FAO estimates that 91 percent of the global food production increase towards the year 2050 should come from yield increases of current arable lands based on the advancement of agricultural research [2].

China's digital economy has expanded rapidly in recent years. While average digitalization of the economy remains lower than in advanced economies, digitalization is already high in certain regions and sectors, in particular e-commerce. Such transformation has boosted productivity growth, with varying impact on employment across sectors. 
Digitalization will continue to reshape the Chinese economy. The government should play an important role in maximizing the benefits of digitalization while minimizing related risks, such as potential labor disruption, privacy infringement, emerging oligopolies, and financial risks [3].

Soybean finds a principal place in the agricultural production systems of many countries including the United States, Brazil, Argentina, China, and India.

\section{The Model}

There are four components of the gross domestic product (real output), ( $Y$ ): (i) consumption, (C); (ii) investment, (I); (iii) government purchases, (G); and (iv) net export $\left(N_{x}\right)$, as follows:

$$
Y_{d, t}=C_{t}+I_{t}+G_{t}+N_{x t}
$$

The consumption function is explained by (Equation (2)), i.e.,

$$
C_{t}=\alpha Y^{2}{ }_{t}-1 \quad 0<\alpha<1
$$

The investment in ICTs that can be used for e-agriculture and soybean production is explained by (Equation (3)), i.e.,

$$
I_{i, t}=\beta Y_{t}-1 \quad 0<\beta<1
$$

where $\beta$ stands for the investment in ICTs ratio. The relation between an investment in ICTs that can be used for e-agriculture and soybean production and investment $(I)$ is:

$$
I_{i, t}=\omega I_{t} \quad 0<\omega<1
$$

where $\omega$ is the ratio showing the amount of investment in ICTs in relation to the total investment. Further, government spending function (Equation (5)) and net export function (Equation (6)) are given as:

$$
\begin{array}{cc}
G_{t}=\gamma Y_{t} & 0<\gamma<1 \\
N_{x, t}=\eta Y_{t} & 0<\eta<1
\end{array}
$$

where $\gamma$ is the government spending ratio and $\eta$ is the net exports ratio. The relation between the real output, $Y_{t}$, and soybean production, $Y_{s, t}$, is:

$$
Y_{s, t}=\delta Y_{t} \quad 0<\delta<1
$$

Now, putting Equations (1)-(7) together, we obtain:

$$
Y_{s, t}=\left[\frac{\beta}{\omega(1-\gamma-\eta)}\right] Y_{s, t-1}-\left[\frac{\alpha}{\delta(\gamma+\eta-1)}\right] Y_{s, t-1}{ }^{2}
$$

It is important to introduce $y s$ as $Y_{s}=Y_{s} / Y_{s}{ }^{m}$, where $0<Y_{s}<1$. In this sense, it is obtained

$$
y_{s, t}=\left[\frac{\beta}{\omega(1-\gamma-\eta)}\right] y_{s, t-1}-\left[\frac{\alpha}{\delta(\gamma+\eta-1)}\right] y_{s, t-1}{ }^{2}
$$

The model given by Equation (9) is called the logistic model.

\section{The Logistic Map}

The iteration process for the logistic map (Equation (10))

$$
z_{t}=\pi z_{t-1}\left(1-z_{t-1}\right), \pi \in[0,4], z_{t} \in[0,1]
$$


is equivalent to the iteration of the growth model (Equation (9)) when we use the identification:

$$
z_{t}=\left[\frac{\alpha \omega(1-\gamma-\eta)}{\beta \delta(\eta+\gamma-1)}\right] y_{s, t} \text { and } \pi=\left[\frac{\beta}{\omega(1-\gamma-\eta)}\right]
$$

In accordance with Equations (9) and (11), we obtain:

$$
\begin{gathered}
z_{t}=\left[\frac{\alpha \omega(1-\gamma-\eta)}{\beta \delta(\eta+\gamma-1)}\right] y_{s, t}=\left[\frac{\alpha \omega(1-\gamma-\eta)}{\beta \delta(\eta+\gamma-1)}\right]\left\{\left[\frac{\beta}{\omega(1-\gamma-\eta)}\right] y_{s, t-1}-\left[\frac{\alpha}{\delta(\eta+\gamma-1)}\right] y_{s, t-1}{ }^{2}\right\}= \\
=\left[\frac{\alpha}{\delta(\eta+\gamma-1)}\right] y_{s, t-1}-\left[\frac{\alpha^{2} \omega(1-\gamma-\eta)}{\beta \delta^{2}(\eta+\gamma-1)^{2}}\right] y_{s, t-1}{ }^{2}
\end{gathered}
$$

In accordance with Equations (10) and (11), we obtain:

$$
\begin{gathered}
z_{t}=\left[\frac{\beta}{\omega(\eta+\gamma-1)}\right]\left[\frac{\alpha \omega(1-\gamma-\eta)}{\beta \delta(\eta+\gamma-1)}\right] y_{s, t-1}\left\{1-\left[\frac{\alpha \omega(1-\gamma-\eta)}{\beta \delta(\eta+\gamma-1)}\right] y_{s, t-1}\right\}= \\
=\left[\frac{\alpha}{\delta(\eta+\gamma-1)}\right] y_{s, t-1}-\left[\frac{\alpha^{2} \omega(1-\gamma-\eta)}{\beta \delta^{2}(\eta+\gamma-1)^{2}}\right] y_{s, t-1}{ }^{2}
\end{gathered}
$$

The dynamic properties of the logistic map (Equation (10)) have been widely analyzed [4,5]. It is obtained that: (i) For parameter values $0<\pi<1$, all solutions will converge to $z=0$; (ii) For $1<\pi<3.57$, there exist fixed points, the number of which depends on $\pi$; (iii) For $1<\pi<2$, all solutions monotonically increase to $z=(\pi-1) / \pi$; (iv) For $2<\pi<3$, fluctuations will converge to $\mathrm{z}=(\pi-1) / \pi$; (v) For $3<\pi<4$, all solutions will continuously fluctuate; (vi) For $3.57<\pi<4$, the solution becomes "chaotic".

\section{Empirical Evidence}

The soybean production growth stability in the period 1991-2015 can be explained by(Equation (12)):

$$
y_{s, t}=\pi Y_{s, t-1}-\sigma Y_{s, t-1}^{2}
$$

where $Y_{s, t}$-soybean production, $\pi=\left[\frac{\beta}{\omega(1-\gamma-\eta)}\right], \sigma=\left[\frac{\alpha}{\delta(\eta+\gamma-1)}\right]$.

Now, it is important to obtain the wave in soybean production movements. Elliot Wave [6] can be identified if we choose the following years in soybean production movements; 1991, 1994, 1996, 2002, 2004, 2007, 2008, 2015. In this case the soybean production movements are divided into: (i) trends (five waves in the direction of the main trend); and (ii) corrections (three corrective waves) (www.fao.org).

Now, the model (Equation (12)) is estimated (see Table 1). According to the logistic map, for $2<\pi<3$, fluctuations of the soybean production converge to $z=(\pi-$ $1) / \pi$. In this case, the equilibrium value is $z=(2.729108-1) / 2.729108$, or $z=0.6336$, or $11,025,767.808$ tonnes. The golden ratio is $z=0.618$.

Table 1. The estimated model (Equation (12)) $R=0.54780$, Variance explained 30.009\%.

\begin{tabular}{ccc}
\hline$N=8$ & $\pi$ & $\sigma$ \\
\hline Estimate & 2.729108 & 1.992962 \\
Std. Err. & 0.340378 & 0.385135 \\
$\mathrm{t}(6)$ & 8.017877 & 5.174711 \\
$\mathrm{p}$-level & 0.000201 & 0.002065 \\
\hline
\end{tabular}

\section{Conclusions}

A key hypothesis of this work is based on the idea that the coefficient $\pi=\left[\frac{\beta}{\omega(1-\gamma-\eta)}\right]$ plays a crucial role in explaining the local growth stability of soybean production, where $\beta$ is the investment in ICTs ratio, $\gamma$ is the share of government spending in the real gross domestic product, $\eta$ is the share of net export in the real gross domestic product, and $\omega$ is the ratio showing the amount of investment in ICTs in relation to the total investment. An 
estimated value of the coefficient $\pi$ (2.729108) confirms the existence of stable fluctuations of soybean production in China in the period under consideration. The equilibrium value of soybean production in China was 11,025,767.808 tonnes in the period 1991-2015. This equilibrium value $(z=0.6336)$ approaches the golden ratio $(z=0.618)$.

Funding: This research received no external funding.

Institutional Review Board Statement: Not applicable.

Informed Consent Statement: Not applicable.

Data Availability Statement: The data presented in this study are openly available in http:/ /www. fao.org/faostat/en/\#data/QC (accessed on 13 February 2020).

Conflicts of Interest: The author declares no conflict of interest.

\section{References}

1. Food and Agriculture Organization of the United Nations, International Telecommunication Union. E-Agriculture Strategy Guide—A Summary. Available online: https://www.fao.org/3/i6909e/i6909e.pdf (accessed on 13 February 2020).

2. Food and Agriculture Organization of the United Nations. Information and Communication Technologies for Sustainable AgricultureIndicators from Asia and Pacific; Sylvester, G., Ed.; Food and Agriculture Organization of the United Nations: Bangkok, Thailand, 2013; ISBN 978-92-5-108107-5.

3. Zhang, L.; Chen, S. China's Digital Economy: Opportunities and Risks; Working Paper No. 19/16; International Monetary Fund: Tokyo, Japan, 2019.

4. Li, T.; Yorke, J. Period Three Implies Chaos. Am. Math. Mon. 1975, 8, 985-992. [CrossRef]

5. May, R.M. Mathematical Models with Very Complicated Dynamics. Nature 1976, 261, 459-467. [CrossRef] [PubMed]

6. Frost, A.J.; Prechter, R.P. Elliott Wave Principle: A Key to Market Behavior, 10th ed.; New Classics Library: Gainesville, GA, USA, 2005. 